\title{
Entrevista com Sírio Possenti
}

\author{
Tamiris Machado Gonçalves ${ }^{1}$ \\ Vanessa Fonseca Barbosa² \\ Pontifícia Universidade Católica do Rio Grande do Sul - Porto Alegre - Rio Grande do Sul - Brasil
}

$\diamond$

\begin{abstract}
Círio Possenti ${ }^{3}$ é graduado em filosofia pela Pontifícia Universidade Católica do Paraná e tem mestrado e doutorado em linguística pela Universidade Estadual de Campinas. É professor titular do Departamento de Linguística do Instituto de Estudos da Linguagem UNICAMP. Atua em diversas áreas da Linguística, com ênfase em Teoria e Análise Linguística, principalmente na subárea da Análise do Discurso, em especial nos campos do humor e da mídia.

Publicou dentre outros títulos: Humor, Língua e discurso (2010); Questões de linguagem: passeio gramatical dirigido (2011); Discurso, estilo e subjetividade (2008); Questões para analistas do discurso (2009); Os humores da língua (2003). Alguns de seus últimos capítulos de livros publicados são: Durações históricas e sua relação com público e privado. In: Lara, G. P.; Limberti, R. P. (Org.). Discurso e (des)igualdade social (2015); Notes sur l'importance du concept de scène d'énonciation. In: Angermuller, Johannes; Philippe, Gilles (Org.). Analyse du discours et dispositifs d'énonciation; (2015).

É membro das seguintes sociedades científicas: GEL - Grupo de Estudos Linguísticos de São Paulo (do qual foi Presidente na gestão 96/97); ABRALIN - Associação Brasileira de Linguística; ALFAL - Associação de Linguística e Filologia da América Latina; ALED - Associación Latinoamericada de Estudios del Discurso; ANPOLL - Associação Nacional de Pós-Graduação em Letras e Linguística (vice-presidente na gestão 2004-2006).

Esta entrevista foi realizada no dia 19 de agosto de 2015, quando o Prof. Dr. Sírio Possenti veio à PUCRS em razão do convite para ministrar a aula inaugural do segundo semestre de 2015 da Faculdade de Letras. Nessa ocasião, antes de apresentar a palestra intitulada Ainda a questão da gramática na escola, o renomado pesquisador concedeu às doutorandas Tamiris Machado Gonçalves e Vanessa Fonseca Barbosa uma entrevista para falar de temas importantes em sua carreira como professor-pesquisador das questões da linguagem.
\end{abstract}

\begin{abstract}
- Professor Sírio Possenti, em 2016, completar-se-ão 20 anos da primeira edição da sua obra Por que (não) ensinar gramática na escola. Gostaríamos de saber a sua opinião sobre a atualidade do material desenvolvido nesta obra, que a mantém dentre as mais lidas e indicadas pelos professores dos cursos de graduação em Letras em diferentes Instituições do Brasil.
\end{abstract}

\footnotetext{
1 Aluna de doutorado no curso de Pós-graduação em Letras, área de concentração em Linguística, da Pontifícia Universidade Católica do Rio Grande do Sul - PUCRS. Bolsista CNPq.

2 Aluna de doutorado no curso de Pós-graduação em Letras, área de concentração em Linguística, da Pontifícia Universidade Católica do Rio Grande do Sul - PUCRS. Bolsista CNPq.

3 Disponível em: <http://buscatextual.cnpq.br/buscatextual/visualizacv. do?id=K4788834J5>. Acesso em: 13 jul. 2016.
}

- Sírio Possenti - Eu já fui convidado, várias vezes, para reescrever, completar e etc. o Por que (não) ensinar a gramática na Escola e eu sempre resisti. Claro, é um livro datado, logo, eu acrescentaria e diria coisas um pouco diferentes, mas eu não mudaria muito sua essência, porque ele tem dois objetivos específicos: um que é, digamos assim, fazer ou retomar afirmações absolutamente óbvias de coisas que a linguística descobriu, ou até um pouco antes, o que se sabia ao lado da linguística, portanto, o livro tem um caráter de divulgação, embora seja um pouco provocador; e o segundo objetivo é essa sugestão de ensino, ou seja, o que você coloca como centro de seu trabalho. Tendo em vista que, na obra, a questão é a gramática e não o texto, o que eu tento fazer é dizer: se 
a escola adotar a gramática num sentido X, (leia-se: no sentido tradicional), eu preferiria que ela não ensinasse; mas, se ela adotar uma concepção $\mathrm{X}$ de gramática, na verdade, qualquer coisa que você faça na sala de aula, acaba sendo, de alguma maneira, a gramática em torno dessa concepção de gramática e não de outras. Então, eu sempre resisti a mudar [o livro], acho que ele é atual, no sentido de que não tem nada que eu julgue ser uma besteira. $\mathrm{O}$ que as pessoas podem se questionar é se eu realmente penso as afirmações feitas ali, e a minha defesa é um parênteses: não é nem por que ensinar, tampouco por que não ensinar a gramática na escola. Por isso, eu diria que sim, que ele é atual; e lamento, na verdade, que esse livro seja tão atual, tendo em vista que, às vezes, as pessoas vêm me pedir autógrafos nos Congressos e eu estou escrevendo a mesma coisa há um tempo, uma questão que já deveria estar vencida e não está. Por quê? Porque se ensina a gramática de uma forma que eu condeno, já que não funciona nem para ensinar a gramática de um ponto de vista estrutural nem para a própria ideia do que a gramática é para uma língua.

- Como um dos grandes pesquisadores da Linguística no Brasil, dentre as principais questões que permeiam o seu trabalho, encontramos a preocupação com, por exemplo, o papel da escola e a postura do professor com relação ao ensino de línguas, às definições de gramática e à noção de "erro". Suas pesquisas, muitas vezes, evidenciam dados que indicam caminhos a um professor em formação, ou seja, que podem auxiliálo no futuro trabalho docente. Embora com vasto material disponível nos estudos linguísticos, muitos relatos de observação na escola ainda demonstram que há o predomínio de um ensino tradicional e normativo nas escolas quando o assunto é a língua. Qual a sua opinião sobre essa realidade? Por que é tão difícil transformar o trabalho com a linguagem nas escolas e o ensino de gramática normativa é tão recorrente?

- Há várias questões nessa pergunta, uma delas pode ser atribuída à formação do professor. Em outras palavras, acho que são poucos os professores que escrevem e leem como uma coisa vital. Isso ocorre por inúmeras razões, pode ser até pelo volume de trabalho; não há muito tempo para ler, teriam de ler de madrugada, sentiriam sono etc. Por outro lado, eu não sei, se tivessem tempo de folga, leriam, escreveriam e fariam muitas notas, por exemplo. Desde o começo da escola, de modo geral, não somos levados a essa história de prática da escrita e da leitura. Predomina a cultura do exercício: aprende-se uma coisa, aplica-se; aprende-se outra, aplica-se também. Dependendo da matéria, repete-se muito, pois se acredita que a repetição faz aprender - como é o caso, por exemplo, da matemática. Logo, acredito que a gramática, nesse contexto, seja uma espécie de "salvaguarda" à questão: "Vamos fazer o quê?" Vamos dar aula de gramática, pois é aquilo que está mais organizado. Há também uma ampla resistência na sociedade letrada, por parte da mídia, da intelectualidade em geral, que é absolutamente medieval nesse ponto; não aceita duas coisas: a primeira delas é que a língua pode mudar, embora a sociedade de modo geral mude, pois se afirma que ninguém mais escreve como Rui Barbosa, no entanto, não se dá conta de que ninguém mais escreve o português dos Séculos XVII ou XIX, uma vez que já se escreve em outra variedade, pois o padrão mudou, a norma mudou etc. E a segunda crença é a de que, estudando gramática, sujeito e predicado etc., aprende-se a fazer frase. Quando, de fato, sabemos que o movimento é ao contrário: as pessoas falam e depois se analisa o que falam. Eu já ouvi, por exemplo, professor de inglês falando que dá aula para crianças e não ensina artigo, ensina apenas os nomes: fala somente maçã, mesa, mas não a maçã, a mesa porque isso seria muito difícil para as crianças. No entanto, eu pergunto: mas e as crianças americanas com a mesma idade desses alunos não falam o artigo, o nome e o verbo? Aí, vem a resposta de que essa seria uma segunda fase, a de aprender a fazer uma frase. Em suma, isso evidencia que há essa ideia arraigada que impede que a gramática ocupe o seu lugar efetivo na escola: fazer análise científica da língua. Assim como aprendemos química, aprendemos gramática; mas isso não é como aprender a andar ou aprender a cozinhar. Eu acredito que essa ideia de insistir no ensino de gramática na escola tem a ver com o tipo de formação do professor, no sentido amplo, como ele foi doutrinado, ou seja, ele aprendeu assim e vai ensinar assim; e tem a ver também com um déficit de formação, que eu sinto, pois a biblioteca típica do nosso professor de português não é grande, e a escrita dele, típica, não é uma escrita elaborada, prática, diária, constante. Ele escreve raras vezes por ano (manifesto, relatório semestral etc.). Tanto que, se ele solicitar uma redação na escola, ele não vai escrever, ele vai fazer outra coisa, como se ele não precisasse mais disso, não precisasse escrever.

- Diz-se que os cursos de Licenciatura em Letras no Brasil estão mais preocupados em formar pesquisadores do que professores de línguas. $O$ senhor concorda com essa afirmação? Como o senhor vislumbra a relação entre formação de pesquisadores e formação de professores?

- O ideal é que o professor seja também pesquisador. Não que ele esteja envolvido com pesquisa de ponta, ao mesmo tempo em que trabalha em uma escola, mas que seja um pesquisador no sentido de compreender as peculiaridades de sua região, de inteirar-se dos dialetos que ali estão. Se o professor, por exemplo, trabalha em uma 
região como em Ijuí - na qual inclusive eu trabalhei algum tempo - ele tem de ser capaz de conhecer as variedades que existem nessa região; os traços característicos das pessoas que ali falam o português. No caso específico de Ijuí, a título de exemplo, o professor tem de atentar-se em quais estruturas há marcas de alemão; em que sentido a língua está mudando nessa região - se seria uma mudança no dialeto ou uma mudança no português como um todo. Digo isso porque eu mesmo, nessa região, já ouvi coisas do tipo "ganhei uma gripe", "ganhei mais fome", estruturas típicas desse lugar, coisas que, em princípio, na escola, seriam corrigidas porque em português temos "pegar uma gripe" e "estar com fome". O professor tem de conhecer a região em que leciona para aproveitar-se dos dados locais para incluir expressões típicas na escola; fazer debates a partir do jornal local, das expressões que encontrar nele. Ser capaz de olhar coisas típicas de uma área, ter olhar investigativo, curioso, compreender os erros, tentar entender sua origem para melhor ajudar ao aluno são atitudes de um professor-pesquisador. É claro que há necessidade de ter cursos de formação para orientar esse olhar investigativo, pois, eventualmente, esse profissional irá precisar convencer diretores e alunos de seus objetivos.

- Há um texto seu, intitulado $O$ pequeno sonho da reescrita, publicado em março de 2015 na revista Língua Portuguesa, em que o senhor trata da postura do professor quanto ao texto dos alunos, dizendo que "O professor deve assumir papel de revisor ou editor $\mathrm{e}$ não de simples corretor ou vigia da língua" e, no final da escrita, afirma ainda que "Nossos alunos merecem aulas de verdade!". Se pudesse, portanto, resumir alguns dos principais pontos que constituem essas "aulas de verdade", quais seriam?

จ Bem, inicialmente pensemos que escritores, autores renomados e jornalistas servem-se do trabalho de revisão. Eu quando sou solicitado a escrever um texto, no mais das vezes, passo por um revisor que me indica ajustes, correções - algumas eu acato, outras negocio -, mas a verdade é que muitas questões de gramática, como os pronomes demonstrativos esse, este, eu não quero saber, não estou disposto a perder tempo com esses pormenores. Essa ideia (de o professor assumir papel de revisor e não vigia da língua) é, de certa forma recente. Quando estive pensando em correções do Enem, questionei-me acerca do porquê de um aluno que teve, por exemplo, três erros de ortografia não poder tirar nota mil? O que é uma redação nota mil? Digamos que uma redação dessas seja mil quando um revisor tirar os problemas que ela tem. Ela é mil do ponto de vista da expressão de conteúdo. Se os escritores podem passar por revisão, se editores podem ter acesso à revisão por que o aluno não pode? $\mathrm{O}$ aluno escreve sobre pressão! O aluno deveria ser tratado como o escritor: ter direito à revisão. Deveria ser pensado que, depois de alguns ajustes, o texto é mil, é oitocentos. Nessa perspectiva, a escrita seria vista como um processo, sobretudo um processo em que há um leitor.

\section{Referências}

POSSENTI, S. O pequeno sonho da reescrita. Língua Portuguesa, v. 9, p. 18-19, 2015.

Durações históricas e sua relação com público e privado. In: LARA, G. P.; LIMBERTI, R. P. (Org.). Discurso e (des)igualdade social. São Paulo: Contexto, 2015. v. 1, p. $49-60$.

Notes sur 1'importance du concept de scène d'énonciation. In: ANGERMULLER, Johannes; PHILIPPE, Gilles (Org.). Analyse du discours et dispositifs d'énonciation; autour les travaux de Dominique Maingueneau. Limoges: Lambert-Lucas, 2015. v. 1, p. 117-123.

Questões de linguagem: passeio gramatical dirigido. São Paulo: Parábola Editorial, 2011. 190p .

Questões para analistas do discurso. São Paulo: Parábola Editorial, 2009. v. 1. 184 p .

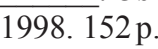

Os humores da língua. Campinas: Mercado de Letras, Por que (não) ensinar gramática na escola. Mercado de Letras, 1996.

Discurso, estilo e subjetividade. São Paulo: Martins Fontes, $1993.218 \mathrm{p}$. 